\title{
Microglia Mediate the Clearance of Soluble A $\beta$ through Fluid Phase Macropinocytosis
}

\author{
Shweta Mandrekar, ${ }^{1}$ Qingguang Jiang, ${ }^{1}$ C. Y. Daniel Lee, ${ }^{1}$ Jessica Koenigsknecht-Talboo, ${ }^{2}$ David $M$. Holtzman, ${ }^{2}$ and \\ Gary E. Landreth ${ }^{1}$ \\ ${ }^{1}$ Alzheimer Research Laboratory, Department of Neurosciences, Case Western Reserve University School of Medicine, Cleveland, Ohio 44106, and \\ ${ }^{2}$ Department of Neurology and Hope Center for Neurological Disorders, Washington University, St. Louis, Missouri 63110
}

\begin{abstract}
Alzheimer's disease is characterized by the progressive deposition of $\beta$-amyloid $(\mathrm{A} \beta)$ within the brain parenchyma and its subsequent accumulation into senile plaques. Pathogenesis of the disease is associated with perturbations in $A \beta$ homeostasis and the inefficient clearance of these soluble and insoluble peptides from the brain. Microglia have been reported to mediate the clearance of fibrillar $\mathrm{A} \beta$ $(\mathrm{fA} \beta)$ through receptor-mediated phagocytosis; however, their participation in clearance of soluble $\mathrm{A} \beta$ peptides $(\mathrm{sA} \beta)$ is largely unknown. We report that microglia internalize $\operatorname{sA} \beta$ from the extracellular milieu through a nonsaturable, fluid phase macropinocytic mechanism that is distinct from phagocytosis and receptor-mediated endocytosis both in vitro and in vivo. The uptake of sA $\beta$ is dependent on both actin and tubulin dynamics and does not involve clathrin assembly, coated vesicles or membrane cholesterol. Upon internalization, fluorescently labeled sA $\beta$ colocalizes to pinocytic vesicles. Microglia rapidly traffic these soluble peptides into late endolysosomal compartments where they are subject to degradation. Additionally, we demonstrate that the uptake of sA $\beta$ and fA $\beta$ occurs largely through distinct mechanisms and upon internalization are segregated into separate subcellular vesicular compartments. Significantly, we found that upon proteolytic degradation of fluorescently labeled sA $\beta$, the fluorescent chromophore is retained by the microglial cell. These studies identify an important mechanism through which microglial cells participate in the maintenance of $A \beta$ homeostasis, through their capacity to constitutively clear $\mathrm{sA} \beta$ peptides from the brain.
\end{abstract}

\section{Introduction}

The deposition of amyloid $\beta(\mathrm{A} \beta)$ in the extracellular space of the brain is a pathological hallmark of Alzheimer's disease (AD). AD pathogenesis is associated with alterations in $\mathrm{A} \beta$ homeostasis resulting in an accumulation of $\mathrm{A} \beta$ peptides within the brain paranchyma (Tanzi and Bertram, 2005; Wang et al., 2006).

Microglia are the brain's tissue macrophages and the primary immune effectors within the CNS. These cells are responsible for normal tissue maintenance and continually sample the extracellular environment. They are highly dynamic and respond rapidly to perturbations within the brain. Additionally, they take up solutes and nutrients through endocytosis (Kreutzberg, 1996; Nimmerjahn et al., 2005).

Endocytosis encompasses three primary mechanisms: phagocytosis, receptor-mediated endocytosis and pinocytosis. Phagocytosis involves the uptake of large particles whose internaliza-

Received Nov. 21, 2008; revised Feb. 5, 2009; accepted March 2, 2009.

This work was supported by grants from the National Institutes of Health [AG030482 (G.E.L.), AG16740 (G.E.L.), T32-HD-007104, F32-AG029044 (J.K.-T.), R37-AG1356 (D.M.H.)], a Kirschstein National Research Service Award [F31-NS061445-01A1 (S.M.)], the American Health Assistance Foundation, and the Blanchette Hooker Rockefeller Foundation. We received support by the Flow Cytometry Core Facility of the Comprehensive Cancer Center of Case Western Reserve University (CWRU) and University Hospitals of Cleveland (P30-CA43703) and the Imaging Core Facility of the Department of Neurosciences at CWRU. We thank Drs. Guojun Bu, Maria Febbrario, and Ralph Isberg providing reagents for this work. We thank Erin Reed-Geaghan, Paige Cramer, and Brandy Wilkinson their comments on this manuscript.

Correspondence should be addressed to Gary E. Landreth, Alzheimer Research Laboratory, Department of Neurosciences, Case Western Reserve University School of Medicine, Cleveland, 0H 44106. E-mail: gel2@cwru.edu. D0I:10.1523/JNEUROSC1.5572-08.2009

Copyright $\odot 2009$ Society for Neuroscience $\quad$ 0270-6474/09/294252-11\$15.00/0 tion is stimulated through its interaction with cell surface receptors, engaging the cell's phagocytic machinery (Stuart and Ezekowitz, 2005). We have previously shown that fibrillar A $\beta$ $(\mathrm{fA} \beta)$ interacts with a multicomponent cell surface receptor complex (Bamberger et al., 2003) stimulating its phagocytic uptake (Knauer et al., 1992; Koenigsknecht and Landreth, 2004). Receptor-mediated endocytosis is a mechanistically distinct process, elicited by ligand binding to a receptor on the cell surface, resulting in the internalization of the receptor and its ligand within clathrin-coated or uncoated vesicles (Mellman, 1996; Conner and Schmid, 2003; Kirkham and Parton, 2005; Mills, 2007). Pinocytosis can occur through two separate pathways: micropinocytosis or macropinocytosis, and is typically associated with the uptake of solutes from the extracellular milieu. Micropinocytotic vesicles are no larger than $0.1 \mu \mathrm{m}$ in diameter and may be caveolin-coated. Micropinosome formation is independent of actin and occurs within cholesterol-rich lipid domains of the plasma membrane (Parton and Richards, 2003). In contrast, macropinocytic vesicles are formed by the closure of membrane ruffles, a process dependent on both actin and tubulin (Swanson and Watts, 1995; Conner and Schmid, 2003).

Soluble or small oligomeric forms of $\mathrm{A} \beta$ have been postulated to have deleterious actions in the brain and promote disease progression (Lue et al., 1999; Lacor et al., 2007) inducing changes in synaptic function, behavioral deficits and promoting neuronal degeneration (Lue et al., 1999; Kim et al., 2003; Lacor et al., 2007). Additionally, levels of sA $\beta$ within human brain tissue has been shown to correlate with disease severity (McLean et al., 1999; 
Wang et al., 1999). Little is known about the intrinsic cellular mechanisms through which sA $\beta$ is cleared from the brain. In the present study we have investigated how microglia take up sA $\beta$. We demonstrate that macropinocytic uptake of $s A \beta$ and its subsequent proteolytic degradation represents a significant mechanism mediating $\mathrm{A} \beta$ clearance from the extracellular milieu. Although internalization of the soluble peptide is not limited to microglia, these cells are the most efficient in the endocytosis of the peptide in vitro. Significantly, we report that microglia can effectively degrade fluorescently labeled $\mathrm{sA} \beta$, but the fluorophores typically used to label these peptides are retained within the cell, demonstrating the limitation of the utility of these preparations.

\section{Materials and Methods}

Reagents. The glutathione S-transferase (GST)-CD36-(93-120) peptide was a gift from Dr. Maria Febrarrio (Cleveland Clinic Foundation, Cleveland, $\mathrm{OH}$ ). Invasin was a gift from Dr. Ralph Isberg (Tufts University, Medford, MA). Cytochalasin D, fucoidin, nocodazole, and filipin were all purchased from Sigma-Aldrich. Cytochalasin D, filipin, and nocodazole were reconstituted in DMSO and fucoidin was dissolved in sterile distilled water. The $4 \mathrm{~N} 1 \mathrm{~K}$ peptide was purchased from Bachem and reconstituted in sterile distilled water. Lamp1 and Lamp2 antibodies were a kind gift from Dr. Douglas M. Fambrough (Johns Hopkins University, Baltimore, MD). RAP was a gift from Dr. Guojun Bu (Washington University, St. Louis, $\mathrm{MO}$ )

Tissue culture. The immortalized BV-2 murine microglial cell line was grown and maintained in DMEM containing gentamycin and 2\% fetal bovine serum in $5 \% \mathrm{CO}_{2}$ (Blasi et al., 1990).

Primary microglial cells were derived from the brains of C57BL/6 mice at postnatal day 1-2 as previously described (McDonald et al., 1997). Cells were maintained in DMEM/F12 (Invitrogen) containing 1\% penicillin/streptomycin and $20 \%$ fetal bovine serum (FBS), $\mathrm{pH}$ 7.4. Astrocytes were separated from the microglial cultures using a mild trypsinization protocol described by Saura et al. (2003).

The SHS5Y, neuronal cell line, was maintained in DMEM/F12 containing $1 \%$ penicillin/streptomycin and $10 \% \mathrm{FBS}$, pH 7.4 in $5 \% \mathrm{CO}_{2}$.

Murine embryonic fibroblasts (MEFs) were isolated from prenatal day 0 embryos and maintained in DMEM containing 10\%FBS and 1\% Pen/ Strep, pH 7.4 in $5 \% \mathrm{CO}_{2}$.

$A \beta$ preparation. Lyophilized $\mathrm{A} \beta_{1-42}$ (American Peptide) was dissolved to a final concentration of $1 \mathrm{mg} / \mathrm{ml}$ in DMSO and stored at $-80^{\circ} \mathrm{C}$ until use. Fluorescently labeled soluble $\mathrm{A} \beta_{1-42}$, was prepared by dissolving the lyophilized peptide to a concentration of $2 \mathrm{~mm}$ in $0.1 \mathrm{M}$ sodium bicarbonate for conjugation with Alexa488 or $50 \mathrm{~mm}$ sodium borate for conjugation with the $\mathrm{Cy} 3$ fluorophore. The $\mathrm{A} \beta$ was labeled with $\mathrm{Cy} 3$ (Amersham Biosciences) or Alexa488 (Invitrogen) according to the manufacturer's protocol. The reaction mixture was allowed to fibrillize at $37^{\circ} \mathrm{C}$ overnight after which unincorporated dyes were removed by ultracentrifugation at $100,000 \times g$ and the supernatant discarded. The pellet was then resuspendend in DMSO, sonicated and subjected to ultracentrifugation at $100,000 \times g$ for $1 \mathrm{~h}$ at $4^{\circ} \mathrm{C}$. The supernatant contains the operationally defined "soluble $\mathrm{A} \beta$," which is likely a mixture of primarily monomeric and small oligomeric species and runs with a mobility corresponding to $4 \mathrm{kDa}$ on SDS-PAGE. Sonication and ultracentrifugation was repeated until most of the pellet fraction was solubilized in DMSO. The remaining pellet was dissolved in sterile $\mathrm{ddH}_{2} \mathrm{O}$ and comprised the $\mathrm{fA} \beta$ preparation. Protein concentration was quantified using the BCA method (Pierce).

Immunocytochemistry. Murine BV-2 microglial cells and primary murine microglia were plated on coverslips in 24 -well plates at a density of $1 \times 10^{5}$ cells/well for $18 \mathrm{~h}$. The media was removed and replaced with serum free DMEM or DMEM/F12 at the time of treatment. Cells were treated with $2 \mu \mathrm{g} / \mathrm{ml}$ soluble Cy3-labeled $\mathrm{A} \beta$ (sCy3-A $\beta$ ) or soluble Alexa488-labeled A $\beta$ (sAlexa488-A $\beta$ ) for 3 h. Cells were washed three times with cold PBS and fixed in $4 \%$ paraformaldehyde and permeabilized with $0.1 \%$ Triton. After permeabilization, cells were stained with
DAPI (10 min). For colocalization studies, after permeabilization, cells were blocked in 5\% normal goat serum for $1 \mathrm{~h}$. Primary antibodies for Lamp1/Lamp2 were used at 1:50 dilution and anti-Rab5B (Santa Cruz, s.c.-598) at 1:250 dilution. Cells were incubated with primary antibodies for $1.5 \mathrm{~h}$ and then washed three times with PBS and incubated with secondary antibodies conjugated to Alexa-fluorophores at a 1:100 dilution for $40 \mathrm{~min}$. Coverslips were mounted on glass slides and observed using a Zeiss LSM 510 confocal microscope.

Uptake of $20 \mathrm{~nm}$ microspheres or $1.0 \mu \mathrm{m}$ beads. BV-2 cells were seeded on coverslips in 24-well plates as described above. Fluorescent $1 \mu \mathrm{m}$ or 20 $\mathrm{nm}$ microspheres (Invitrogen) were blocked with $0.5 \mathrm{mg} / \mathrm{ml} \mathrm{BSA}$ in $50 \%$ PBS solution. Cells were incubated with microspheres or beads for 20 min before they were fixed, permeabilized and stained with DAPI (Koenigsknecht and Landreth, 2004). Coverslips were mounted on glass slides and observed using a Zeiss LSM 510 confocal microscope.

Flow cytometry. Murine microglial BV-2 cells and primary murine microglia were plated at a density of $5 \times 10^{5}$ cells/well in a six-well plate overnight in DMEM containing 2\% FBS. The following morning the media was replaced with serum-free DMEM and cells were incubated with $2 \mu \mathrm{g} / \mathrm{ml}$ sAlexa488-A $\beta$ for $3 \mathrm{~h}$. For experiments in which antagonists were used, BV-2 cells were incubated with the inhibitor for $30 \mathrm{~min}$ before the addition of sA $\beta(2 \mu \mathrm{g} / \mathrm{ml})$. Cells were then washed with cold PBS and fixed with $4 \%$ paraformaldehyde. Following fixation, cells were washed with PBS and collected for analysis by flow cytometry using the EPICS-XL MCL.

Live cell imaging. BV-2 microglial cells were plated on Delta T tissue culture plates at a density of $5 \times 10^{5}$ cells/plate. Cells were incubated overnight in DMEM containing 2\% FBS. The following day, culture media was replaced with serum-free DMEM and live cell imaging was performed using a Zeiss LSM 510 confocal microscope. Both Cy3-A $\beta$ (2 $\mu \mathrm{g} / \mathrm{ml}$ ) and Lysotracker (Invitrogen, Green DND-26) were added to the culture media at the same time. Lysotracker was used according to the manufacturer's protocol.

Two-photon microscopy. The cranial window procedure was performed on 7-month-old Cx3crl/Gfp ${ }^{+/+}$mice as described previously (D'Amore et al., 2003; Brendza et al., 2005). Briefly, the mice were anesthetized with avertin before placement in a stereotaxic device. After removal of the hair and cleaning the skin with $70 \%$ isopropanol, the skin was cut away from the eyes to the base of the skull. A circle was carved in the skull $\sim 8 \mathrm{~mm}$ in diameter that crossed the midline and was just slightly anterior to both bregma and $\lambda$. This portion of the skull was removed and the exposed brain region was irrigated with PBS and packed with gel foam. Gel foam was removed and Cy3 labeled soluble A $\beta$ was placed on the surface of the brain. The exposed brain region was then covered with a piece of coverglass held in place by dental cement and super glue.

A ring of paraffin was placed over the dental cement to create a chamber to hold water for imaging. Approximately $45 \mathrm{~min}$ after the Cy3 labeled sA $\beta$ was placed on the brain the anesthetized mouse was placed on the stage of a two-photon microscope (Zeiss LSM 510 Meta NLO system with Coherent Chameleon Ti:Sa laser). For simultaneous imaging of GFP and $\mathrm{Cy} 3$ a wavelength of $900 \mathrm{~nm}$ was used. Fluorescence emission of GFP and Cy 3 was collected in the ranges of 500-550 nm and LP560 nm filter settings respectively.

After in vivo imaging the mouse was assessed to confirm deliverance of the $\mathrm{sA} \beta$ peptide in the brain. Following in vivo imaging the brain, the mouse was perfused with PBS containing $0.3 \%$ heparin and the brain was removed. The brain was immersion fixed in $4 \%$ paraformaldehyde for $24 \mathrm{~h}$ before being placed in $30 \%$ sucrose. Brains were sectioned at 20 micron on a cryostat and images were obtained as a $\mathrm{Z}$-series stack using the Zeis LSM 510 confocal microscope.

Western blotting. BV-2 cells were plated in 6 well plates at a density of $5 \times 10^{5}$ cells/well. After $18 \mathrm{~h}$ of incubation in DMEM containing $2 \%$ FBS, media was replaced with serum-free DMEM. Cells were then incubated with unlabeled or Alexa488-labeled A $\beta$ for $3 \mathrm{~h}$. Cells were washed with cold PBS and lysed using RIPA buffer containing protease inhibitor cocktail (Sigma-Aldrich). Protein concentrations of the cell lysates were measured using the BCA method. Western blot analysis of $\mathrm{A} \beta$ was performed on $4-12 \%$ Bis-Tris gels (Invitrogen). $\mathrm{A} \beta$ was detected using the 
anti-human $\mathrm{A} \beta$ antibody, 6E10 (Covance), at a 1:2000 dilution and was detected by enhanced chemiluminescence (Pierce). $\beta$-Tubulin (Santa Cruz, s.c.-5274) served as a loading control.

ELISA. BV-2 cells were plated overnight in 24 -well plates at a density of $1 \times 10^{5}$ cells/well in DMEM containing 2\% FBS. Cells were incubated in fresh serum-free DMEM containing 2 $\mu \mathrm{g} / \mathrm{ml}$ of soluble Alexa-488 or Cy3 labeled or unlabeled $\mathrm{A} \beta$ peptides $(2 \mu \mathrm{g} / \mathrm{ml})$ for $3 \mathrm{~h}$. Cells were lysed in $1 \%$ SDS-containing protease inhibitor cocktail. $A \beta$ ELISA's were performed using 6E10 (Covance) as the capture antibody and 4G8-HRP (Covance, SIG-39245-200) as the detection antibody. Synthetic $A \beta_{1-42}$ was used to generate a standard curve. Plates were developed using a TMB substrate kit (Pierce) and the reaction was stopped by the addition of an equal volume of $1 \mathrm{M} \mathrm{HCl}$. The results were read using a Spectramax colorimetric plate reader (Molecular Devices).

\section{Results}

Microglia take up both soluble and fibrillar forms of $\mathrm{A} \boldsymbol{\beta}$

To elucidate the mechanism used by microglia to take up soluble forms of $A \beta$, we derivatized sA $\beta$ with $\mathrm{Cy} 3$ or Alexa 488 fluorescent chromophores. When these fluorescently labeled sA $\beta$ preparations were resolved on a $4-12 \%$ Bis-Tris gel, a majority $(>90 \%)$ of $\operatorname{sA} \beta$ was found to have an apparent molecular weight of $\sim 4 \mathrm{kDa}$, and only low levels of more slowly migrating materials, corresponding to small $\mathrm{A} \beta$ oligomers, were observed. No fibrillation of the peptides was detected when $\mathrm{sA} \beta$ was incubated at $2 \mu \mathrm{g} / \mathrm{ml}$ in culture medium for up to $18 \mathrm{~h}$ and analyzed by SDS-PAGE (data not shown). Fluorescent labeling of $\mathrm{A} \beta$ allowed for the development of a fluorescence-activated cell sorting (FACS) based assay that was used to monitor $A \beta$ internalization by microglia. Previous studies have used immunofluorescence to monitor $\mathrm{A} \beta$ uptake; however, FACS has rarely been used to characterize $A \beta$ internalization and has allowed us to quantitatively measure the uptake of sA $\beta$ (Knauer et al., 1992; Ard et al., 1996; Paresce et al., 1997; Chu et al., 1998; Chung et al., 1999; Koenigsknecht and Landreth, 2004; Simakova and Arispe, 2007).

We monitored $\mathrm{A} \beta$ uptake by microglia and found that both BV-2 microglia and primary microglial cells were able to take up soluble as well as fibrillar species of Cy3-A $\beta$ (Fig. 1). However, the subcellular distribution of the two species of $A \beta$ was quite different. Soluble $\mathrm{A} \beta$ was localized in a diffuse pattern throughout the entire cell (Fig. $1 A, C$ ), in contrast to fA $\beta$ which was confined to large phagocytic vesicles within the cytoplasm (Fig. $1 B, D$ ). We evaluated the uptake of both Alexa488-labeled sA $\beta$ and fA $\beta$ using FACS analysis. Both BV-2 cells and primary microglia were able to take up the labeled $A \beta$ species at comparable levels. The intracellular levels of fibrillar $\mathrm{A} \beta$ were higher in both cell types in comparison to $\mathrm{sA} \beta$ when similar levels of exogenous $\mathrm{A} \beta$ peptide were added to the culture medium (Fig. $1 E, F$ ), although quantitative conclusions cannot be drawn because of the different physical forms of the $A \beta$ peptides. Importantly, the intracellular distribution of the peptides suggests that internalization of soluble and fibrillar $\mathrm{A} \beta$ occur through distinct mechanisms.

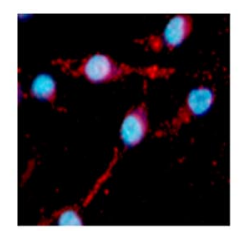

Merge

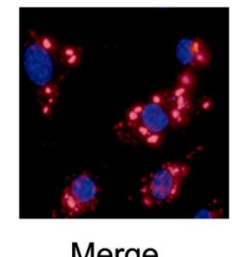

Merge

64

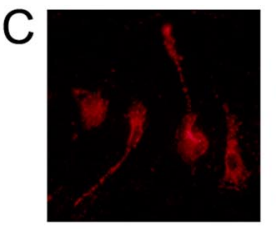

sCy3-A $\beta$

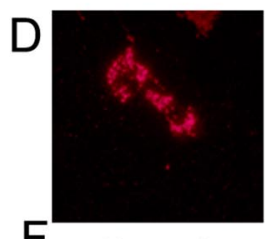

fCy3-A $\beta$

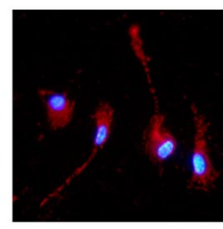

Merge

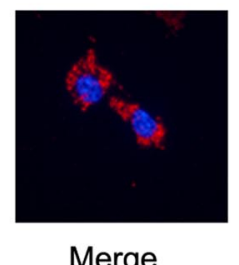

Merge

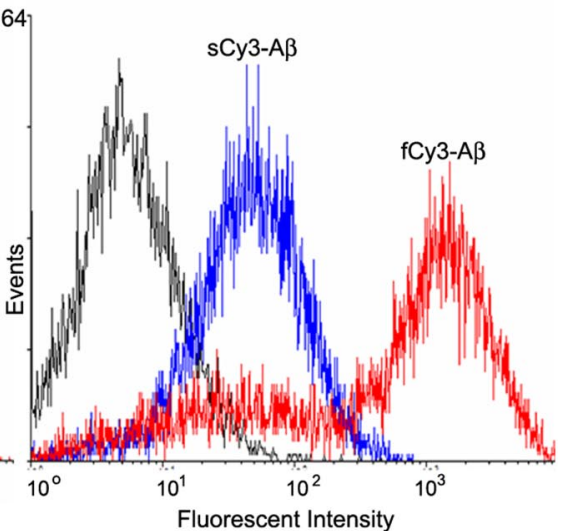

Fluorescent Intensity

Figure 1. Microglial cells can take up both soluble and fibrillar species of $A \beta$. $A-F, B V-2$ microglial cells $(A, B, E)$ and primary were then fixed, permeabilized, and stained with DAPI. $\boldsymbol{E}, \boldsymbol{F}$, Uptake was quantified using flow cytometry on the EPICS-XL MCL in $\mathrm{BV}-2$ cells $(\boldsymbol{E})$ as well as primary microglia $(\boldsymbol{F})$ and compared with control non treated cells (black trace).

We verified that microglia in the living brain take up and compartmentalize sA $\beta$. We monitored the internalization of sCy3-A $\beta$ by microglial cells in vivo in a C $\times 3 \mathrm{crl} / \mathrm{Gfp} \mathrm{p}^{+/+}$mouse model (Fig. 2). These mice possess microglial cells that express green fluorescence protein (eGFP). Fluorescent, sCy3-A $\beta$ was applied to the surface of the brain and its uptake into microglia was evaluated $3 \mathrm{~h}$ later. We found that microglia internalize the sA $\beta$ peptides and traffic them into intracellular vesicles. The sA $\beta$ appears perinuclear in its intracellular distribution, similar to that in BV-2 cells and primary microglia. These data suggest that the mechanisms of $\mathrm{sA} \beta$ uptake are similar both in vitro and in the living brain (Fig. $2 \mathrm{~B}, \mathrm{C}$ ) and that microglia are proficient at clearing both soluble and fibrillar species of $\mathrm{A} \beta$ from the extracellular space.

\section{Soluble $A \boldsymbol{\beta}$ is not taken up through phagocytosis or receptor-mediated endocytosis}

To determine the mechanism of sA $\beta$ entry into microglia, we examined the kinetics of $\mathrm{sA} \beta$ uptake. We found that Alexa488labeled sA $\beta$ was taken into BV-2 cells in a time (Fig. $3 A, B$ ) and concentration (Fig. $3 C$ ) dependent manner. The uptake of the sA $\beta$ peptide appears to occur through a nonsaturable mechanism, suggesting this process may be independent of cell surface receptors.

The cellular mechanisms responsible for internalization of sA $\beta$ peptides, until now, have not been well characterized. However, previous studies have shown that phagocytosis of fA $\beta$ requires the interaction of the $\mathrm{A} \beta$ fibrils with a cell surface receptor 


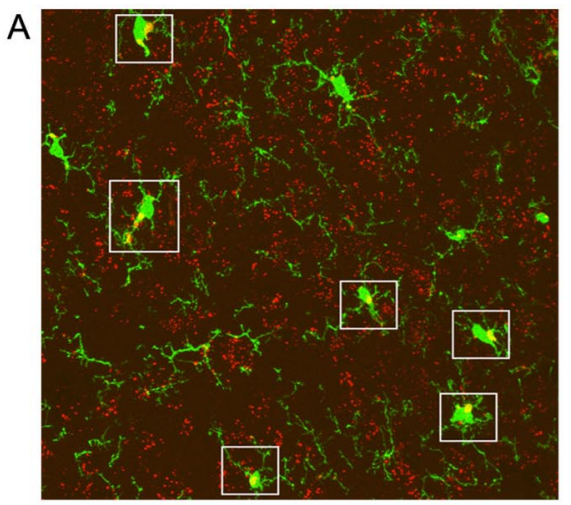

$20 x$

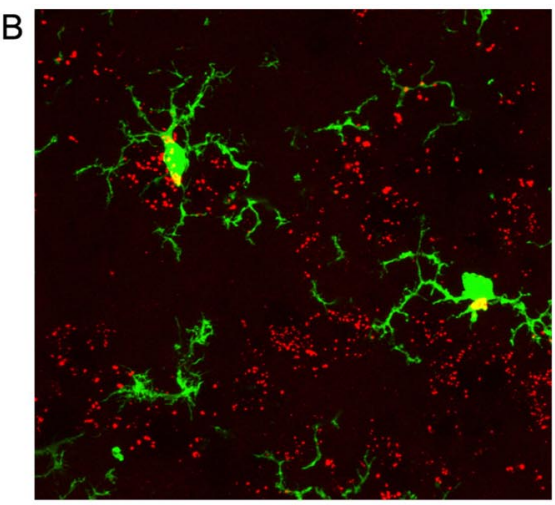

$100 x$

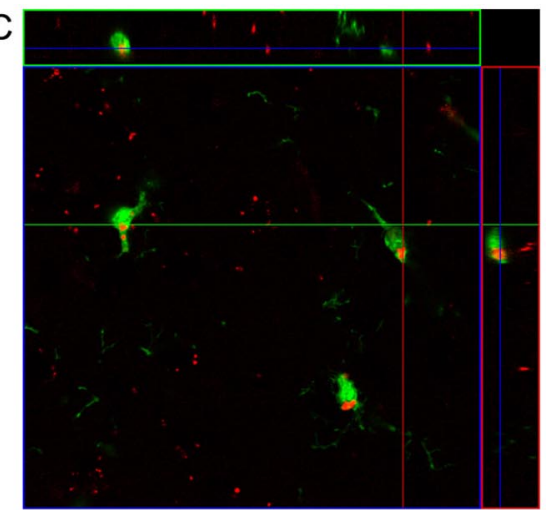

100x Cross-Section

Figure 2. Microglia cells internalize $\mathrm{SCy} 3-\mathrm{A} \beta$ in vivo. A craniotomy was performed on a $\left(x 3 \mathrm{Cr} 1 / \mathrm{Gfp}{ }^{+/+}\right.$mice and the brain was exposed to $1-2 \mu \mathrm{g}$ ofs $\mathrm{Cy} 3-\mathrm{A} \beta$. After $3 \mathrm{~h}$ of exposure to the peptide the mouse was perfused and the brains isolated and sectioned. $\boldsymbol{A}-\boldsymbol{C}$, Confocal images were obtained using the $20 \times$ (microglia that have taken internalized sCy3-A $\beta$ are boxed in white) $(\boldsymbol{A})$ and $100 \times(\boldsymbol{B}, \boldsymbol{C})$ objectives. Confocal images of microglial cells that have internalized sCy3-A $\beta$ are shown in the $x$ and $y$ planes $(\boldsymbol{C})$.

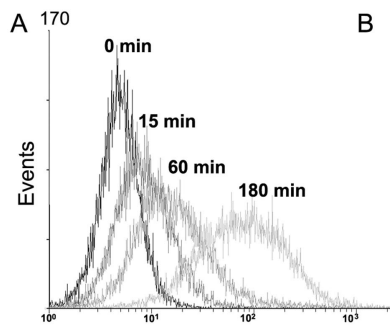

Fluorescent Intensity

$B$

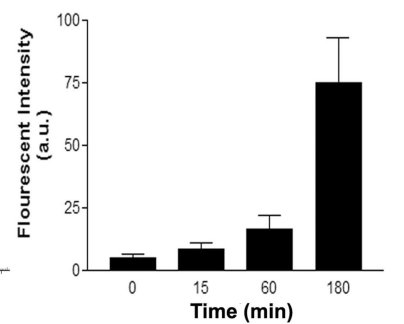

C

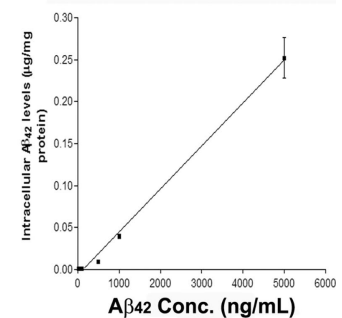

Figure 3. Time course and dose-dependence of $s A \beta$ uptake. $\boldsymbol{A}, \boldsymbol{B}, \mathrm{BV}-2$ cells were incubated for the indicated times with 2 $\mu \mathrm{g} / \mathrm{ml}$ soluble-Alexa488-A $\beta$, fixed, and analyzed by flow cytometry on the EPICS-XL MCL. C, BV-2 cells were incubated for $3 \mathrm{~h}$ with increasing concentrations of soluble $A \beta$, cells were lysed and intracellular $A \beta$ levels were evaluated by ELISA.

complex composed of the B-class scavenger receptor CD36, the $\alpha 6 \beta 1$ intergrin and the integrin associated protein, CD47 (Bamberger et al., 2003; Koenigsknecht and Landreth, 2004). To determine whether this receptor complex plays a role in the internalization of $\mathrm{sA} \beta, \mathrm{BV}-2$ cells were incubated with antagonists specific to the individual components of this receptor complex that serve to block fA $\beta$-stimulated phagocytosis (Koenigsknecht and Landreth, 2004). Receptor antagonists were added to the culture medium $30 \mathrm{~min}$ before the addition of sAlexa488-A $\beta$. CD47 is a transmembrane receptor that interacts with integrins and modulates integrin dependent signaling. Its activity is necessary for both interaction of $\mathrm{fA} \beta$ with microglial cells as well as fA $\beta$ induced phagocytosis (Bamberger et al., 2003; Koenigsknecht and Landreth, 2004). 4N1K, an agonist peptide, is derived from the cell-binding domain of thrombosondin-1 (TSP-1), and interacts competitively with other CD47 ligands for CD47 binding (Chung et al., 1997). Fucoidin inhibits both scavenger receptor class A and class B interactions (Husemann et al., 2002). Treatment of microglial cells with $4 \mathrm{~N} 1 \mathrm{~K}$ or fucoidin did not inhibit uptake of $\mathrm{sA} \beta$ by BV-2 cells. Treatment of microglial cells with $4 \mathrm{~N} 1 \mathrm{~K}$ enhanced the uptake of sA $\beta$ into microglial cells. CD 47 has been shown to interact with $\beta$-family integrins and modulate their response. Treatment of cells with $4 \mathrm{~N} 1 \mathrm{~K}$ has been shown to promote cell spreading and migration in a number of cells via interaction with CD47. $4 \mathrm{~N} 1 \mathrm{~K}$ acts to stimulate membrane ruffling and therefore increases uptake of sA $\beta$ by microglial cells (Chung et al., 1997; Brown and Frazier, 2001). A peptide antagonist of the $\beta$-class scavenger receptor, CD36 (Frieda et al., 1995; Chung et al., 1997; Husemann et al., 2002) also failed to block the internalization of $\mathrm{sA} \beta$ into the cells. We have previously shown that interactions between the microglial cell and fibrillar $\mathrm{A} \beta$ peptides is restricted to the same domains required for TSP-1 binding, which include amino acids 93-102 of CD36 (Coraci et al., 2002; Bamberger et al., 2003). The GSTCD36 peptide, is comprised of the extracellular binding domain of CD36 coupled to a GST tag, and blocks the interactions between CD36 receptor and other ligands (Frieda et al., 1995). The $\beta 1$-integrin action was inhibited using INV195, a truncated form of invasin, a Yersinia protein that specifically binds this integrin subunit (Wiedemann et al., 2001) and blocks its interaction with fA $\beta$ (Koenigsknecht and Landreth, 2004). The full-length form of invasin, Inv397, binds the $\beta 1$-integrin and stimulates an intracellular signaling cascade inducing phagocytosis. This peptide was used to determine the role of this molecule in sA $\beta$ uptake (Isberg et al., 2000; Wiedemann et al., 2001). Neither inhibition, nor activation of the $\beta 1$-integrin affected the internalization of sA $\beta$ into BV-2 microglial cells (Fig. $4 A$ ).

In addition to the fA $\beta$ receptor complex, the low-density lipoprotein receptor related protein-1 (LRP-1) has been implicated in the uptake and clearance of $\mathrm{A} \beta$ (Wiedemann et al., 2001; Deane et al., 2004; Harris-White and Frautschy, 2005; Bu et al., 2006; Sagare et al., 2007). LRP plays a role in the internalization as well as the degradation of lipoproteins and has been shown to mediate fA $\beta$ endocytosis (Harris-White et al., 2004). To test the role of LRP in uptake of $\mathrm{sA} \beta, \mathrm{BV}-2$ microglial cells were incubated with the LRP antagonist, receptor associated protein (RAP), for $30 \mathrm{~min}$ before the addition of sAlexa488-A $\beta$. RAP chaperones the folding of LRP and has been shown to compete strongly with all other LRP ligands, functionally antagonizing the actions of this receptor (Iadonato et al., 1993). When assessed by flow cytometry, blocking LRP with RAP had no effect on sA $\beta$ internalization by microglia (Fig. 4B).

An alternate means through which cells can internalize solutes from the extracellular milieu is through clathrin-mediated endocytosis. The uptake of transferrin has been shown to occur through this mechanism (Bleil and Bretscher, 1982). To determine whether $\mathrm{sA} \beta$ is internalized through a clathrin-coated ves- 
icle mechanism, colocalization studies were performed using Alexa488-labeled transferrin and $\mathrm{sCy} 3-\mathrm{A} \beta$. We found no colocalization between transferrin and $\mathrm{sA} \beta$ within early endosomes (Fig. 4C), indicating that initial internalization of the proteins occurs via distinct subpopulations of vesicles. Together, these data suggest that sA $\beta$ is not taken up into microglial cells through a receptor-mediated mechanism. To verify this conclusion, a competition assay was performed. BV-2 cells were treated for $3 \mathrm{~h}$ with $2 \mu \mathrm{g} / \mathrm{ml}$ of sAlexa488-A $\beta$ in the presence of increasing concentrations of unlabeled $\mathrm{sA} \beta$ peptides. The samples were then fixed and analyzed by flow cytometry. If $\operatorname{sA} \beta$ is internalized via a receptor-dependent mechanism, then the addition of unlabeled sA $\beta$ should compete with the uptake of the fluorescently labeled $\mathrm{sA} \beta$ species. We demonstrate that increasing levels of unlabeled sA $\beta$ had no effect on the uptake of fluorescent sA $\beta$ by microglial cells as observed by FACS analysis (Fig. 5). These data suggest that the mechanism of sA $\beta$ uptake occurs through a nonsaturable, fluid phase mechanism.

\section{Microglia take up sA $\beta$ through fluid phase macropinocytosis}

Fluid-phase pinocytosis includes two distinct mechanisms, macropinocytosis and micropinocytosis. Macropinocytosis results in the formation of vesicles that are between $0.2 \mu \mathrm{m}$ and $5.0 \mu \mathrm{m}$ in diameter and are created by the enclosure of membrane ruffles. Micropinocytosis occurs via the formation of vesicles within cholesterol-rich lipid domains. These vesicles can also be caveolin-coated (Nichols, 2003). To determine the route of sA $\beta$ entry, BV-2 cells were treated with nocodazole and cytochalasin $\mathrm{D}$, which inhibit tubulin depolymerization and actin polymerization, respectively. Both cytoskeletal structures are necessary for the formation of membrane ruffles and the subsequent formation of macropinosomes (Conner and Schmid, 2003; WehrleHaller and Imhof, 2003). Treatment of BV-2 cells with both of these agents significantly reduced uptake of sA $\beta$ by BV- 2 cells, as measured by flow cytometry (Fig. $6 A, B$ ). However, treatment of cells with filipin, which depletes membrane cholesterol and inhibits micropinocytosis from lipid domains (Fujita et al., 1981), did not affect sA $\beta$ internalization (Fig. $6 C$ ). These data indicate that sA $\beta$ enters microglial cells via fluid phase macropinocytosis.

Once internalized, $\mathrm{sA} \beta$ is rapidly trafficked into the lysosomes via the endolytic pathway. Colocalization between $\mathrm{sCy} 3-\mathrm{A} \beta$ and Lysotracker was seen within 15 min of $A \beta$ peptide treatment in BV-2 cells using real time imaging techniques (Fig. 7D; supplemental Videos 1, 2, available at www.jneurosci.org as supplemental material). Previous work has shown that $\mathrm{fA} \beta$ is trafficked to the lysosomes after phagocytosis (Paresce et al., 1997; Majumdar et al., 2007). Trafficking of sA $\beta$ appears to occur by transfer to the late endosomes and lysosomes by direct fusion of the macropinocytic vesicle to these late endolytic vesicles. Soluble $\mathrm{A} \beta$ colocalizes directly with Lamp1/Lamp2 (Fig. $7 A, B$ ), markers of late endolytic pathway, but not with Rab5B, a marker of early endosomes (Stein et al., 2003) (Fig. 7C). Together, these data demonstrate that $\mathrm{sA} \beta$ enters microglial cells via fluid phase macropinocytosis, a mechanism that is distinct from classic receptormediated endocytic pathways.

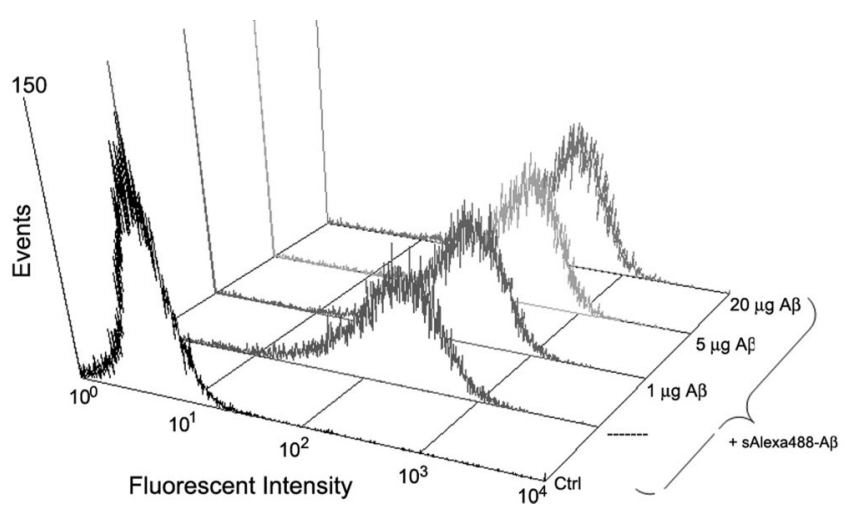

Figure 5. Microglia take up $s A \beta$ through a nonsaturable mechanism. BV-2 cells were incubated for $3 \mathrm{~h}$ with $2 \mu \mathrm{g} / \mathrm{ml}$ of soluble Alexa488-A $\beta$ in the presence of the indicated amounts of unlabeled soluble $A \beta$ peptide. Cells were then fixed and analyzed using flow cytometry on the EPICS-XL MCL.

\section{Soluble and fibrillar species of A $\beta$ localize to different intracellular compartments}

Consistent with a pinocytic uptake mechanism, sA $\beta$ was colocalized with $20 \mathrm{~nm}$ microspheres which are commonly used to monitor pinocytic uptake (Falcone et al., 2006) (Fig. $8 A$ ). In addition, the $1 \mu \mathrm{m}$ beads taken up through phagocytic mechanisms were rarely found to colocalize with the $20 \mathrm{~nm}$ microspheres, consistent with their different mechanisms of uptake (Fig. $8 B, D$ ). However, the $20 \mathrm{~nm}$ microspheres, given their small size, can also enter phagocytic vesicles and, in some cases, can be seen partially colocalized with the $1 \mu \mathrm{m}$ beads (Fig. $8 B, C$ ). Importantly, sAlexa488-A $\beta$ and fCy3-A $\beta$ are largely localized to different cellular compartments after being taken up by BV-2 cells. We found a fraction of $\mathrm{sA} \beta$ colocalized to vesicles carrying $\mathrm{fA} \beta$ suggesting some sA $\beta$ enters phagocytic vesicles and can also be taken up when this mechanism is active because of bulk uptake of extracellular fluid upon phagosome formation (Fig. $8 E, F$ ). The largely distinct subcellular distribution of both fibrillar and soluble $\mathrm{A} \beta$ peptides is evidence of their different modes of entry into the cell, through a phagocytic mechanism and fluid phase macropinocytosis, respectively. 


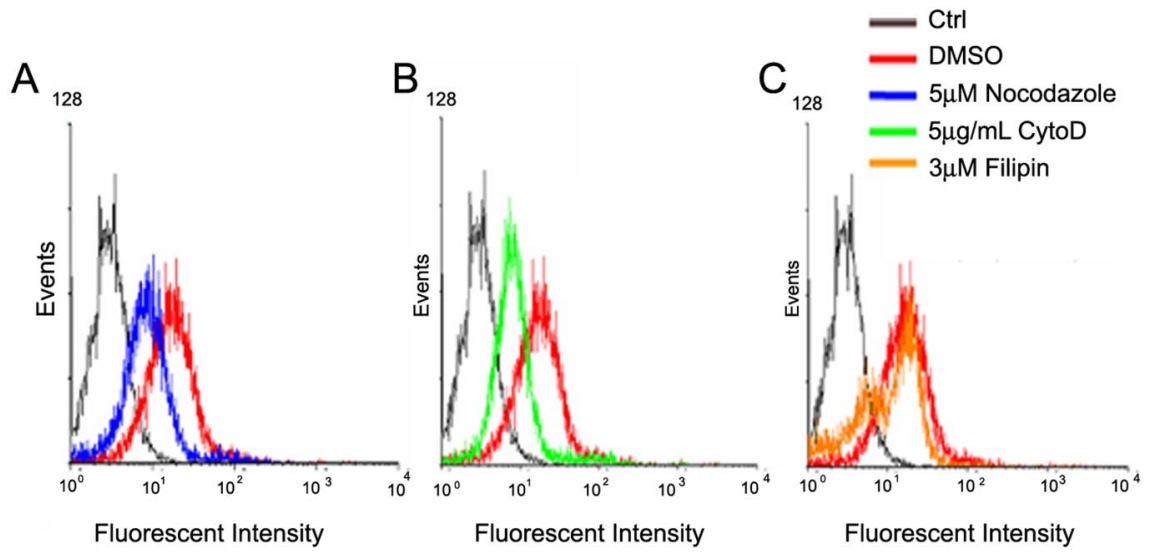

Figure 6. Microglial cells internalized $s A \beta$ through macropinocytosis. $\boldsymbol{A}-\boldsymbol{C}, \mathrm{BV}-2$ cells were incubated with nocodazole, an agent that that disrupts microtubule dynamics $(\boldsymbol{A})$ and cytochalasin $D$, an inhibitor of actin polymerization $(\boldsymbol{B})$ or filipin, a cholesterol-depleting agent ( $\boldsymbol{C}$ ) for 30 min before the addition of soluble Alexa88-sA $\beta$ for $3 \mathrm{~h}$. Cells were then fixed and analyzed using flow cytometry on the EPICS-XL MCL.

\section{Uptake of sA $\beta$ by other cell types}

The macropinocytic uptake of sA $\beta$ is reflective of the capacity of the various cell types to form membrane ruffles. The closure of these membrane ruffles results in the formation of endocytic vesicles allowing the cells to nonspecifically take up the contents of the extracellular milieu. In addition to microglia, both neurons and astrocytes have the capacity to internalize sAlexa488-A $\beta$ (Fig. $9 B, C, F, G)$. Quantitative analysis has revealed that microglial cells take up sAlexa488-A $\beta$ much more efficiently than other cell types under the same conditions (Fig. 9D). Astrocytes are heterogeneous with respect to their ability to take up $A \beta$, one population of cells can internalize $\mathrm{sA} \beta$ just as efficiently as microglial cells while another population does not take up any A $\beta$ at all (Fig. $9 F)$. The basis of this effect is presently unclear. Mouse embryonic fibroblasts (MEFs), a cell type not found in the CNS can also efficiently internalize the sA $\beta$ peptide (Fig. $9 A$ ) and has an uptake profile similar to astrocytes. The subcellular distribution of sA $\beta$ in all three cell types is quite similar to that observed in microglia, with $\mathrm{A} \beta$ distributed within vesicles throughout the cytoplasm (Fig. 9A-C).

\section{Fluorescent labeling of $s A \boldsymbol{\beta}$ does not alter its susceptibility to proteolysis}

The fluorescently labeled $\mathrm{A} \beta$ species have been useful in examining $A \beta$ uptake and trafficking, but we found that they have limited utility in examining the subsequent clearance of the peptide by microglia. To determine whether fluorescently labeled sA $\beta$ was susceptible to proteolytic degradation, the internalization as well as degradation of labeled and unlabeled peptides were measured using flow cytometry and ELISA respectively. BV-2 cells were incubated with $2 \mu \mathrm{g} / \mathrm{ml}$ Alexa488-labeled or unlabeled A $\beta$ peptides for $3 \mathrm{~h}$ then the media was removed and replaced with serum-free DMEM. Cells were incubated for another $3 \mathrm{~h}$ and then monitored for intracellular levels of $\mathrm{sA} \beta$.

We found that unlabeled and Alexa488 conjugated $\mathrm{A} \beta$ preparations were taken up at equivalent levels by BV-2 cells (data not shown). Importantly, all species of $s A \beta$, either labeled or unlabeled, were degraded efficiently, as measured by ELISA. We found that $\sim 50 \%$ of the internalized sA $\beta$ was degraded following $3 \mathrm{~h}$ incubation in either BV-2 cells (Fig. $10 \mathrm{~A}$ ) or primary microglia (Fig. $10 B$ ). In control studies, $A \beta$ levels in the media were also monitored to control for resecretion of the peptide back into the media; however, no $\mathrm{A} \beta$ was detected in the media (Fig. 10C).
Interestingly, when FACS analysis of the sAlexa488-A $\beta$ conjugated peptide was carried out, we did not observe a parallel decrease in intracellular fluorescent intensity (Fig. 10D). Similarly, the fluorescent intensity of fixed cells that internalized $\mathrm{Cy} 3$ conjugated $\mathrm{sA} \beta$ did not diminish following washout despite the fact that over $50 \%$ of the labeled protein was degraded when $\mathrm{A} \beta$ levels were measured by ELISA (Fig. $10 \mathrm{E}$ ). These data may resolve the controversial findings reported by Paresce et al. (1997), who observed that microglia remain fluorescent following uptake of fibrillar $\mathrm{Cy} 3-\mathrm{A} \beta$ for up to $6 \mathrm{~d}$ in culture. This was interpreted as an inability of microglia to degrade fA $\beta$, but could be explained by retention of the fluorophore within the cell. The unconjugated $\mathrm{Cy} 3$ or Alexa488 fluorophores are not taken up by microglial cells (data not shown); therefore, all fluorescent signal observed intracellularly is reflective of internalized sA $\beta$ peptides. The fluorescent derivatization of the peptide, therefore, serves as an excellent tool to examine $\mathrm{A} \beta$ uptake, but cannot be used to evaluate $\mathrm{A} \beta$ degradation.

\section{Discussion}

The response of microglial cells to amyloid deposition has been extensively studied in Alzheimer's disease. Fibrillar forms of A $\beta$ arise from the polymerization of the soluble, monomeric or oligomeric forms of the $\mathrm{A} \beta$ peptide. Despite the abundance of activated microglia, they are inefficient in clearing fA $\beta$ deposits (Rogers and Lue, 2001; Bolmont et al., 2008). Thus, the regulation of sA $\beta$ levels is a critical determinant in the development of $\mathrm{AD}$ pathology. This manuscript focuses on how microglia, one of the many cell types found in the CNS, participates in the maintenance of $\mathrm{A} \beta$ homeostasis. We show that microglia clear $\mathrm{sA} \beta$ species through the process of macropinocytosis both in vitro and in the living brain.

The levels of $\mathrm{A} \beta$ peptides within the brain are tightly regulated by mechanisms controlling their generation and clearance (Tanzi and Bertram, 2005). In the brain, $\sim 8 \%$ of total $A \beta$ is synthesized per hour and cleared at a roughly equal rate, thus, preventing its accumulation and deposition in the normal brain (Bateman et al., 2006). However, modest perturbations in $A \beta$ clearance will result in accumulation of sA $\beta$ peptides within the brain and their subsequent deposition into plaques. It is possible that the inflammatory environment, characteristic of the $\mathrm{AD}$ brain, may affect the ability of microglia to macropinocytose $s A \beta$ from the milieu, acting to promote disease pathogenesis.

Macropinocytosis is a common mechanism used by many cell types for the bulk phase uptake of fluids and nutrients from the environment. This process occurs through the closure of membrane ruffles creating vesicles capable of entering the endolytic pathway (Swanson and Watts, 1995; Falcone et al., 2006). Macropinocytosis has been extensively studied in dendritic cells which use this pathway to take up proteins for antigen presentation (Sallusto et al., 1995; Norbury, 2006) and in Dictyostelium, which employs macropinocytosis to internalize fluids and nutrients in bulk phase (Cardelli, 2001; Amyere et al., 2002). Macropinocytosis has also been implicated in a number of disease mechanisms. For example, macrophages use this mechanism to take up lipids leading to the formation of foam cells (Kruth et al., 


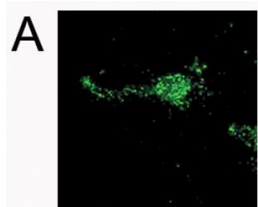

Lamp1

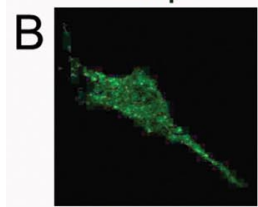

Lamp2

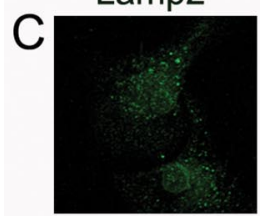

Rab5b
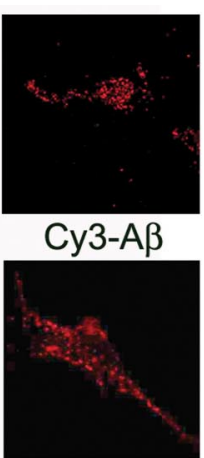

Су3-A $\beta$

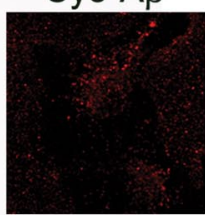

Суз-А

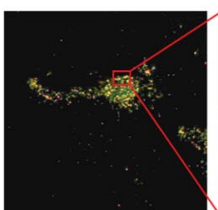

Merged

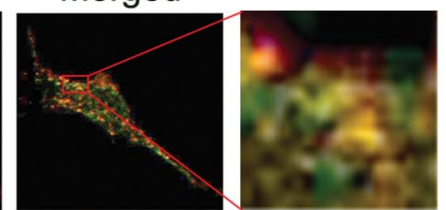

Merged

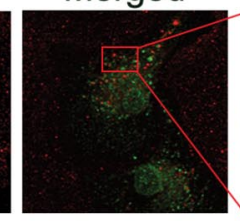

Merged
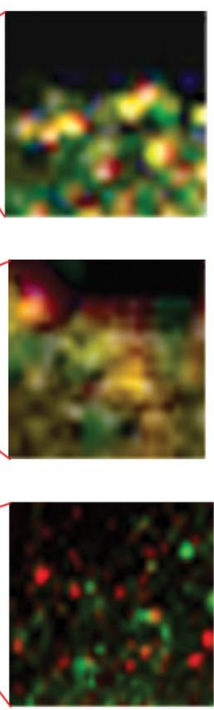
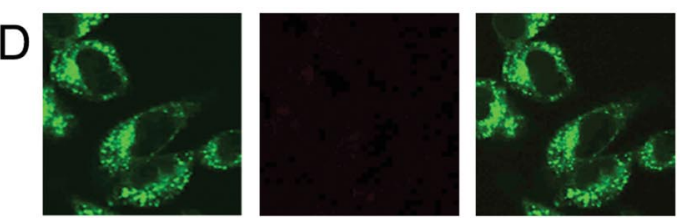

$0 \min$
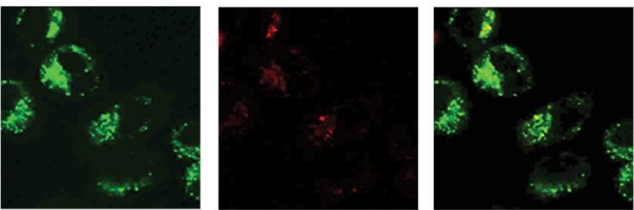

$12 \min$

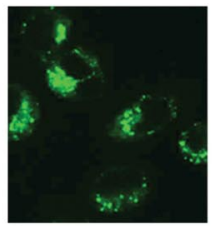

Lysotracker

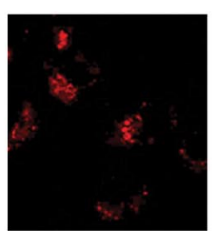

Су3-A $\beta$

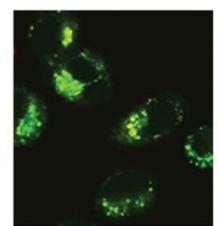

Merged

Figure 7. Upon internalization $s A \beta$ is trafficked into late endosomes and lysosomes. BV-2 microglia were incubated with $2 \mu \mathrm{g} / \mathrm{ml}$ sCy3-A $\beta$ for $3 \mathrm{~h}$, after which they were fixed. $\boldsymbol{A}-\boldsymbol{C}$, Lysosomes were visualized using Lysotracker or LAMP1/2 (markers of late endosomes and lysosomes) $(\boldsymbol{A}, \boldsymbol{B})$ and early endosomes were labeled using Rab5B ( $\boldsymbol{C}$ ). (ells were then imaged on a Zeiss 510 confocal microscope. $\boldsymbol{D}$, Real time imaging was performed using Lysotracker (lysosomal marker) and soluble Cy3-A $\beta$.

2005). Most recently, it has been reported that macropinocytosis mediates HIV-1 infection in trophoblastic cells (Maréchal et al., 2001; Vidricaire and Tremblay, 2007). Depending on the cell type, macropinocytosis can be constitutive or induced. Resting ramified microglia in rat brain slices, as well as in tissue culture exhibit high levels of constitutive pinocytic activity (Ranson and Thomas, 1991).

Our results illustrate that microglial cells can internalize sA $\beta$ by constitutive, nonsaturable, fluid phase macropinocytosis both in vitro and in vivo (Fig. 2). We have ruled out the involvement of receptor-mediated endocytic processes as well as phagocytosis in sA $\beta$ uptake by microglia. Inhibition of $\mathrm{fA} \beta$ receptor components as well as LRP had no effect on sA $\beta$ uptake. Furthermore, competition assays using increasing concentrations of unlabeled sA $\beta$ peptides did not affect internalization of fluorescently labeled peptide, demonstrating this process is nonspecific, nonsaturable and not receptor dependent (Fig. 5). These findings are consistent with our failure to find colocalization of sA $\beta$ with transferrin, which is taken up through receptor-mediated, clathrin coated, endocytosis. These studies indicate that $\mathrm{fA} \beta$ receptor complex, LRP or other receptor-mediated forms of endocytosis do not play a role in $\mathrm{sA} \beta$ internalization.

Macropinocytosis is dependent on both actin and microtubule dynamics which are necessary for the formation of membrane ruffles and the subsequent development of macropinocytic vesicles (Chhabra and Higgs, 2007; Gao et al., 2007). Consistent with the idea that $\mathrm{sA} \beta$ is taken up by microglia through this mechanism, inhibition of actin polymerization (Cytochalasin D) or preventing the depolymerization of microtubules (nocodazole) significantly reduced accumulation of sA $\beta$ intracellularly (Fig. 6A,B). This pathway is distinct from micropinocytosis which forms small vesicles $<0.1 \mu \mathrm{m}$ in diameter and occurs in cholesterol-rich lipid raft domains (Cardelli, 2001). Inhibiting micropinocytosis by cholesterol depletion using filipin had no effect on $\mathrm{sA} \beta$ uptake (Fig. $6 C$ ).

Internalized $\mathrm{sA} \beta$ is rapidly delivered to the lysosomes via the late endolytic pathway. Direct uptake of particles into late endolytic vesicles has been shown to be a characteristic of macropino- cytosis in Dictyostelium (Cardelli, 2001). These vesicles are Lamp $1 / 2$ positive and negative for Rab5B (Fig. $7 A-C)$. This process is rapid and accumulation and colocalization of the $\mathrm{sA} \beta$ can be seen by real time imaging in Lysotracker-positive vesicles within minutes of exposure (Fig. 7D; supplemental Videos 1, 2, available at www.jneurosci.org as supplemental material). Interestingly, this pathway is characteristic of soluble, but not fibrillar $\mathrm{A} \beta$ uptake. Colocalization studies showed that $\mathrm{sA} \beta$ and $\mathrm{fA} \beta$ are initially trafficked to different compartments within the cells, suggesting that distinct mechanisms of entry are used by different species of $A \beta$ (Fig. 8). This observation is consistent with previous work which demonstrated that microglia segregate different sized fluorescent dextran beads into distinct endo-lysosomal vesicles based on their size (Berthiaume et al., 1995). Once internalized, $\mathrm{A} \beta$ microaggregates, have been shown to colocalize to cellular fractions containing the lysosomal markers $\beta$-hexosaminidase and acid phosphatase (Knauer et al., 1992). Furthermore, these microaggregates exhibit perinuclear distribution and colocalize to vesicles containing $\alpha 2 \mathrm{M}$, indicating their trafficking into lysosomal vesicles (Knauer et al., 1992; Paresce et al., 1997; Chung et al., 1999). In a recent study, using two-photon imaging, microglial cells were shown to play a role in the plaque dynamics in an AD transgenic mouse model. Microglia were observed to internalize plaque fragments and deliver them to the lamp2-positive vesicles (Bolmont et al., 2008). These data suggest that although the initial uptake of $\operatorname{sA} \beta$ and $\mathrm{fA} \beta$ occurs through distinct mechanisms both species are ultimately trafficked to the lysosomes. However, since macropinocytic vesicles range in size from 0.5 to $5 \mu \mathrm{m}$ in diameter, it is possible that larger oligomeric species of $A \beta$ are internalized via macropinocytosis as well.

Importantly, this study demonstrates that labeling of $A \beta$ peptides with a fluorophore is a valuable tool to measure cumulative $\mathrm{A} \beta$ uptake by microglial cells. It must be emphasized; however, that the conjugation of a fluorescent chromophore to this particular peptide does not alter its intracellular degradation. We observed that the labeled $\mathrm{sA} \beta$ protein was proteolytically degraded with the same efficiency as the unlabeled peptide (Fig. 10B,C). This latter finding is inconsistent with a previous report that over 

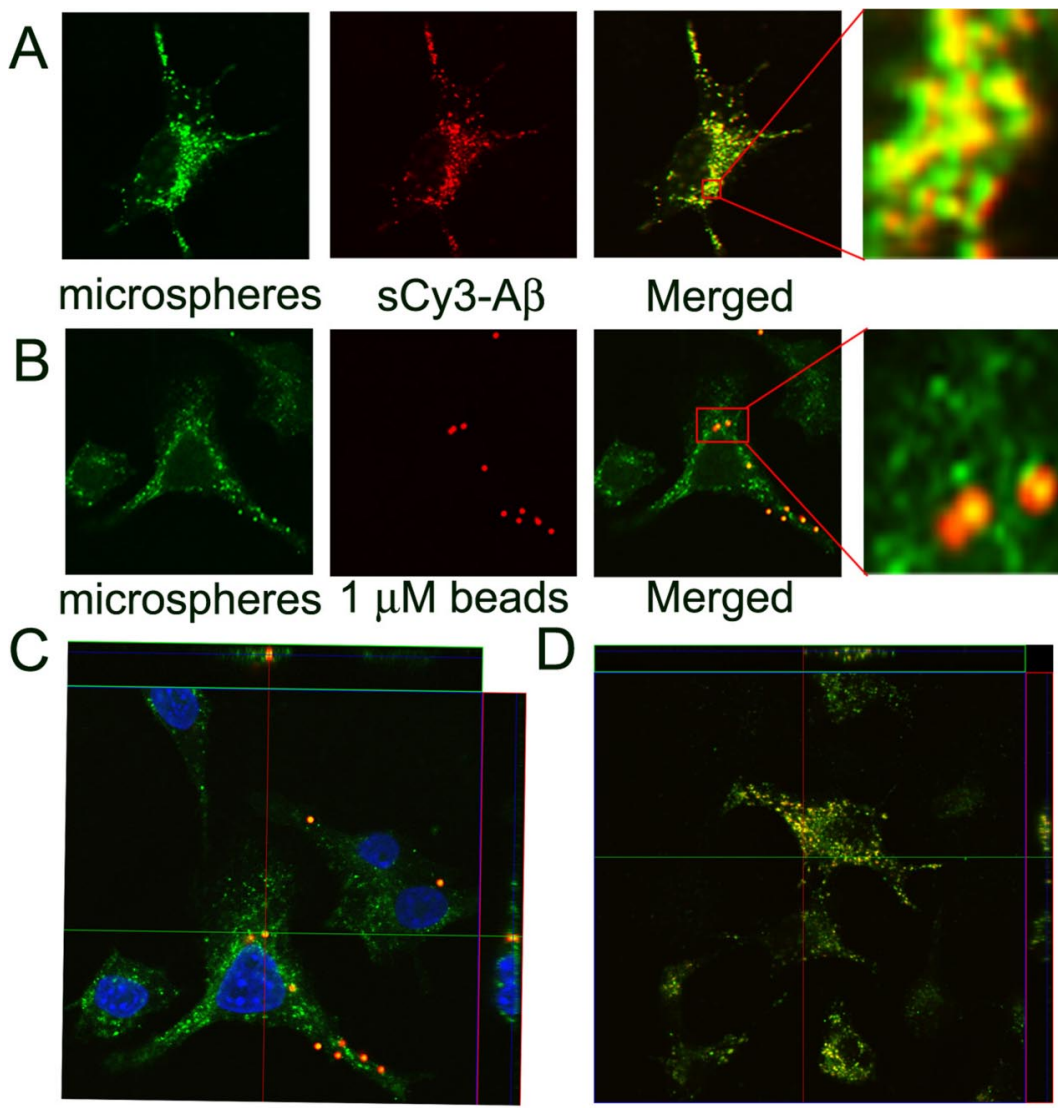

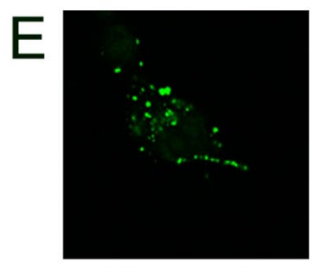

fCy3-A $\beta$
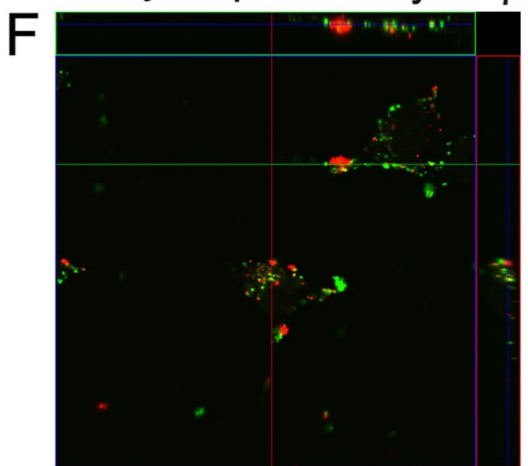

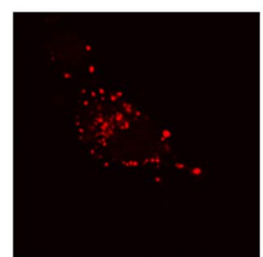

$s C y 3-A \beta$

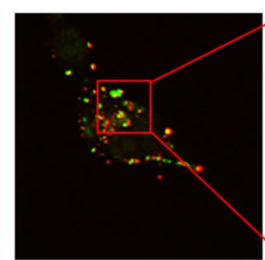

Merged

Figure 8. Soluble and Fibrillar $A \beta$ are internalized through distinct mechanisms. BV-2 microglia were incubated with soluble Cy3-A $\beta$ and $20 \mathrm{~nm}$ fluorescent microspheres (green) for $1 \mathrm{~h}$. $\boldsymbol{A}, \boldsymbol{D}$, The cells were then fixed and visualized. Uptake of $20 \mathrm{~nm}$ microspheres colocalized with sCy3-A $\beta(\boldsymbol{A})$ the colocalization is also visible in the $x$ and $y$ planes $(\boldsymbol{D})$. Uptake of $1 \mu \mathrm{m}$ beads (red) occurs through phagocytosis. $\boldsymbol{B}$, When both microspheres and $1 \mu \mathrm{m}$ beads were coincubated they showed distinct subcellular distributions indicating different mechanisms of uptake. $\boldsymbol{C}$, Confocal images of BV-2 cells that have internalized $1 \mu \mathrm{m}$ beads as well as $20 \mathrm{~nm}$ microspheres from $\boldsymbol{B}$ are shown in the $x$ and $y$ planes. $\boldsymbol{A}, \boldsymbol{F}$, Fibrillar $C y 3-A \beta$, which is taken up through phagocytosis and soluble Alexa488-A $\beta$, which is taken up through pinocytosis were coincubated for $1 \mathrm{~h}$ before fixation $(\boldsymbol{D})$ their distribution in the $x$ and $y$ planes $(\boldsymbol{F})$.

$80 \%$ of internalized $\mathrm{sA} \beta$ is resecreted back into the culture medium by microglia within $10 \mathrm{~h}$ of initial uptake (Chung et al., 1999). Under similar conditions, we observed no resecretion of the peptide into the media as measured by ELISA (Fig. 10D).

Paresce and colleagues have shown that Cy3-labeled microag-
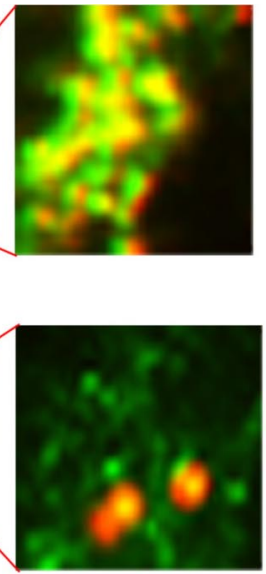

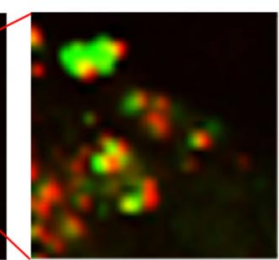

gregates of $\mathrm{A} \beta$ were internalized by microglial cells and reported that they were resistant to degradation for over $6 \mathrm{~d}$ in culture, leading to the conclusion that microglia cannot degrade fA $\beta$ (Paresce et al., 1997). In contrast, our data demonstrates that the labeled soluble peptide is intracellularly degraded; however, the fluorescent chromophore is retained by the cells and can be detected using both flow cytometry as well as in fixed cells. (Fig. 10C,D). These findings provide a possible explanation for the persistent fluorescent signal attributed to the Cy3 microaggregates observed by Paresce et al. The use of fluorescently labeled $\mathrm{A} \beta$ species, are a useful tool to evaluate $A \beta$ uptake and trafficking; however, caution must be exercised when using these modified proteins to evaluate their degradation.

Recently, a debate has arisen over the role and ability of bone marrow derived microglia to cross the blood-brain barrier (BBB) and clear A $\beta$ in the brain. Simard et al. (2006) have reported that these peripherally derived cells transit the $\mathrm{BBB}$ and are capable of clearing $A \beta$ deposits from the brain, whereas resident CNS microglia have an impaired ability to phagocytose $\mathrm{A} \beta$. However, two recent publications have shown that under physiological conditions, peripherally derived monocytes and macrophages are unable to cross the BBB. The ability of macrophage to enter the CNS was shown to be an artifact of the irradiation and reconstitution of bone marrow of the host animal (Ajami et al., 2007; Mildner et al., 2007).

In addition to microglia, both astrocytes and neurons have been postulated to play a role in $A \beta$ clearance. Adult, but not neonatal, mouse astrocytes have been shown take up and degrade fibrillar $A \beta$ deposits from brain slices of transgenic animals expressing the human amyloid precursor protein. Uptake of $A \beta$ deposits into astrocytes was demonstrated to be dependent on scavenger receptors as well as ApoE (Wyss-Coray et al., 2003; Koistinaho et al., 2004). It has been suggested that the uptake of small oligomeric species of $A \beta$ by neurons occurs through a caveolaeindependent, lipid raft-dependent mechanism on distal axons and is transported to the cell body in a retrograde manner (Saavedra et al., 2007). Another study showed that the internalization of $\mathrm{sA} \beta$ is facilitated by the $\alpha 7$ nicotinic acetylcholine receptor in both brain slices and neuronal cultures (Nagele et al., 2002). However, the precise mechanism of internalization remains to be elucidated. Importantly, while neurons and astrocytes have been shown to have the ability to take up $A \beta$, it is unclear whether they have the capacity to degrade this peptide. 

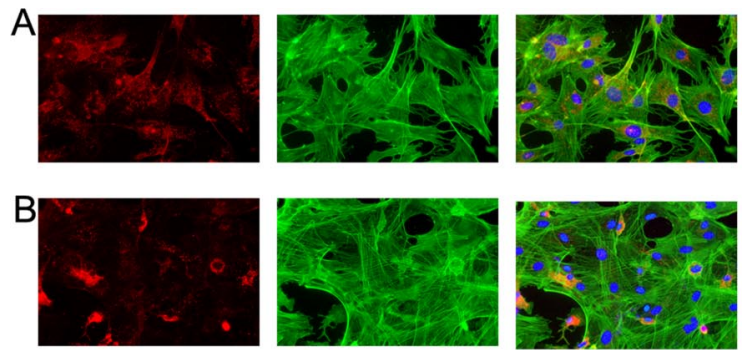

Astrocytes
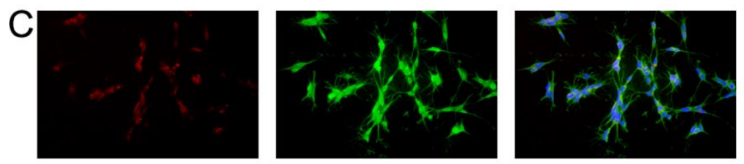

Neurons

MEFs

$\mathrm{E}$

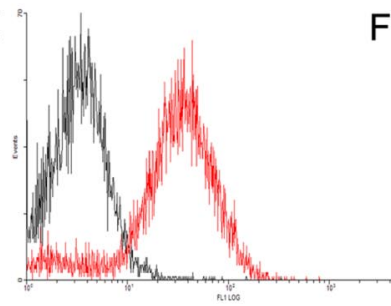

Microglia

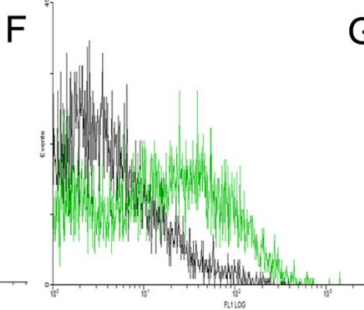

Astrocytes

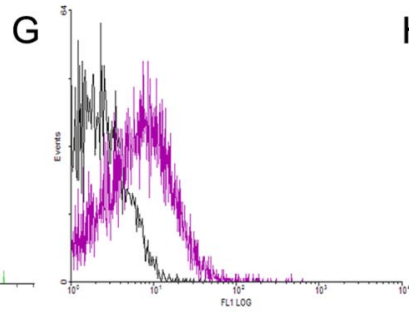

Neurons
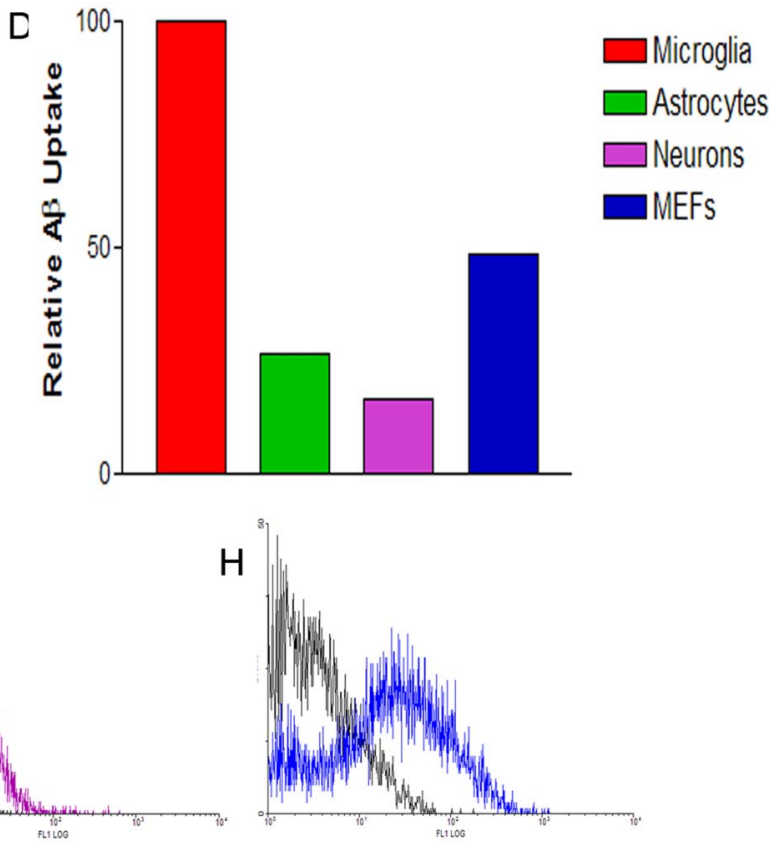

MEFs

Figure 9. Internalization $S A \beta$ is not unique to microglia. Astrocytes, neurons, primary microglia or MEFs were plated at a density of 800,000 cells/well of a six-well plate and incubated with 2 $\mu \mathrm{g} / \mathrm{ml}$ of soluble $C \mathrm{y} 3$ labeled $\mathrm{A} \beta$ or Alexa488 labeled $\mathrm{A} \beta$ peptide for $6 \mathrm{~h}$. $\boldsymbol{A}-\boldsymbol{H}$, The internalization of $\mathrm{s} A \boldsymbol{\beta}$ was visualized using the Leica DMIRB research microscope $(\boldsymbol{A}-\boldsymbol{C})$ or by flow cytometry on the EPICS-XL MCL $(\boldsymbol{D}-\boldsymbol{H})$. The cells were then fixed and permeabilized, stained with DAPI and phalloidin and mounted on coverslips. $\boldsymbol{D}$, The mean fluorescent intensity of internalized $A \beta$, is shown and specific values are as follows: 28.29 (microglia), 7.56 (astrocytes), 4.71 (neurons), and 13.67 (MEFs).

In the present study we have demonstrated that internalization of $\operatorname{sA} \beta$ is not limited to microglia, as both astrocytes and neurons are capable of taking up sA $\beta$ as assessed by flow cytometry (Fig. 9). Since macropinocytosis is a ubiquitous process and each cell has the capacity to pinocytose, this process is not unique to microglial cells and may play a more widespread role in the clearance and homeostasis of $\mathrm{sA} \beta$ in the brain by multiple cell types. However, our studies demonstrate that microglial cells are the most efficient at this process in vitro, internalizing almost four times more sA $\beta$ than astrocytes (Fig. 9D). Additionally, we show that microglia are also efficient at degrading sA $\beta$ (Fig. 10). We speculate that microglia more readily take up sA $\beta$ than other cell types in vivo, based on our in vitro analysis, as a result of more active membrane ruffling and process extension and retraction in the course of their normal surveillance functions in the CNS (Davalos et al., 2005; Nimmerjahn et al., 2005). These studies characterize the mechanism microglia employ in the clearance of sA $\beta$ peptides, suggesting they may play a more abundant role in the maintenance of $\mathrm{A} \beta$ homeostasis in the brain.

\section{References}

Ajami B, Bennett JL, Krieger C, Tetzlaff W, Rossi FM (2007) Local selfrenewal can sustain CNS microglia maintenance and function throughout adult life. Nat Neurosci 10:1538-1543.

Amyere M, Mettlen M, Van Der Smissen P, Platek A, Payrastre B, Veithen A, Courtoy PJ (2002) Origin, originality, functions, subversions and molecular signalling of macropinocytosis. Int J Med Microbiol 291:487-494.

Ard MD, Cole GM, Wei J, Mehrle AP, Fratkin JD (1996) Scavenging of Alzheimer's amyloid beta-protein by microglia in culture. J Neurosci Res 43:190-202.

Bamberger ME, Harris ME, McDonald DR, Husemann J, Landreth GE (2003) A cell surface receptor complex for fibrillar beta-amyloid mediates microglial activation. J Neurosci 23:2665-2674.

Bateman RJ, Munsell LY, Morris JC, Swarm R, Yarasheski KE, Holtzman DM
(2006) Human amyloid-beta synthesis and clearance rates as measured in cerebrospinal fluid in vivo. Nat Med 12:856-861.

Berthiaume EP, Medina C, Swanson JA (1995) Molecular size-fractionation during endocytosis in macrophages. J Cell Biol 129:989-998.

Blasi E, Barluzzi R, Bocchini V, Mazzolla R, Bistoni F (1990) Immortalization of murine microglial cells by a v-raf/v-myc carrying retrovirus. J Neuroimmunol 27:229-237.

Bleil JD, Bretscher MS (1982) Transferrin receptor and its recycling in HeLa cells. EMBO J 1:351-355.

Bolmont T, Haiss F, Eicke D, Radde R, Mathis CA, Klunk WE, Kohsaka S, Jucker M, Calhoun ME (2008) Dynamics of the microglial/amyloid interaction indicate a role in plaque maintenance. J Neurosci 28:4283-4292.

Brendza RP, Bacskai BJ, Cirrito JR, Simmons KA, Skoch JM, Klunk WE, Mathis CA, Bales KR, Paul SM, Hyman BT, Holtzman DM (2005) AntiAbeta antibody treatment promotes the rapid recovery of amyloidassociated neuritic dystrophy in PDAPP transgenic mice. J Clin Invest 115:428-433.

Brown EJ, Frazier WA (2001) Integrin-associated protein (CD47) and its ligands. Trends Cell Biol 11:130-135.

Bu G, Cam J, Zerbinatti C (2006) LRP in amyloid-beta production and metabolism. Ann N Y Acad Sci 1086:35-53.

Cardelli J (2001) Phagocytosis and macropinocytosis in Dictyostelium: phosphoinositide-based processes, biochemically distinct. Traffic 2:311-320.

Chhabra ES, Higgs HN (2007) The many faces of actin: matching assembly factors with cellular structures. Nat Cell Biol 9:1110-1121.

Chu T, Tran T, Yang F, Beech W, Cole GM, Frautschy SA (1998) Effect of chloroquine and leupeptin on intracellular accumulation of amyloid-beta (A beta) 1-42 peptide in a murine $\mathrm{N} 9$ microglial cell line. FEBS Lett 436:439-444.

Chung H, Brazil MI, Soe TT, Maxfield FR (1999) Uptake, degradation, and release of fibrillar and soluble forms of Alzheimer's amyloid beta-peptide by microglial cells. J Biol Chem 274:32301-32308.

Chung J, Gao AG, Frazier WA (1997) Thrombspondin acts via integrinassociated protein to activate the platelet integrin alphaIIbbeta3. J Biol Chem 272:14740-14746. 

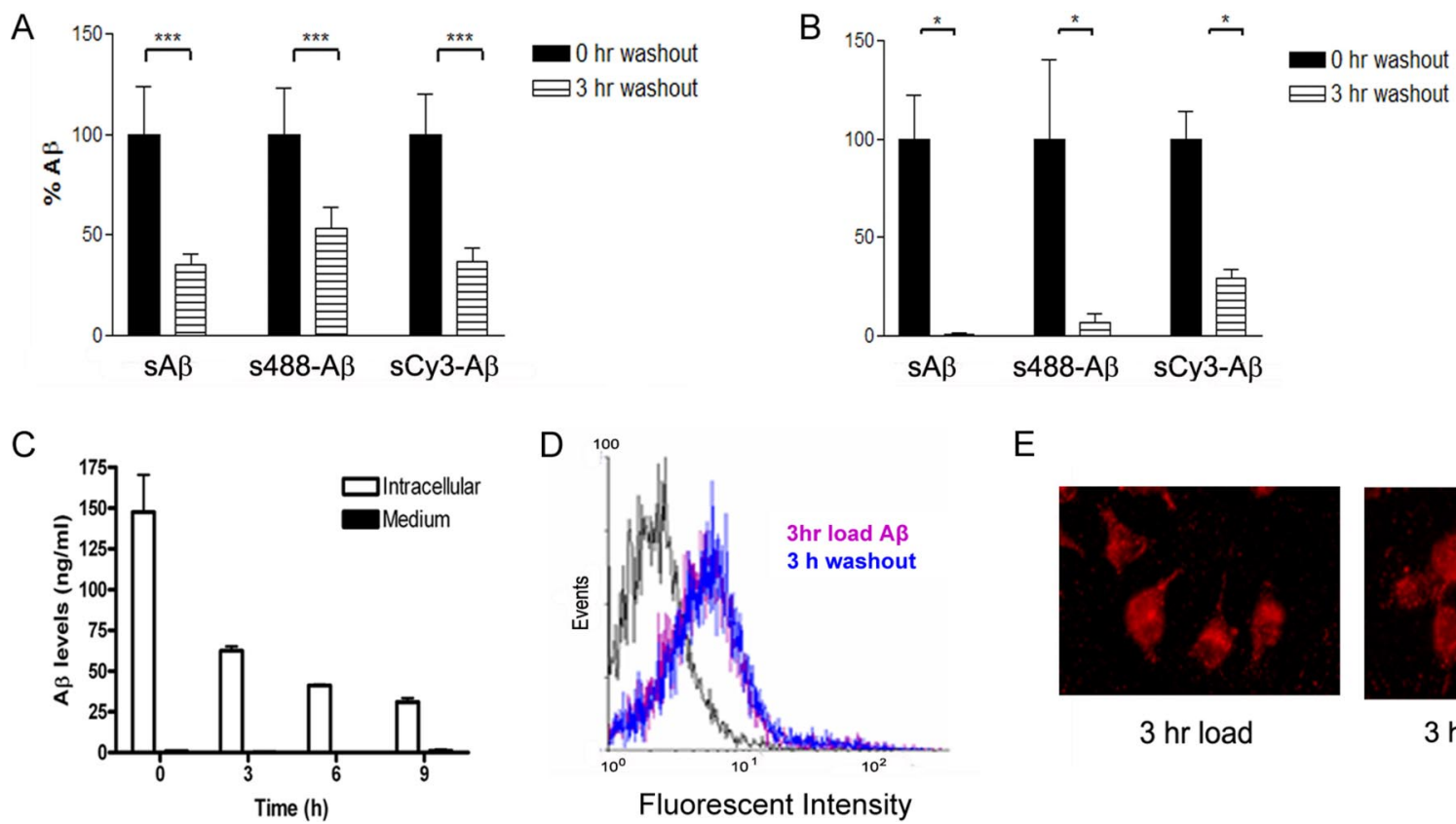

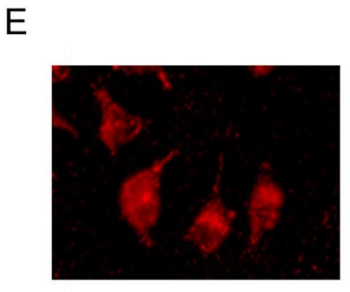

$3 \mathrm{hr}$ load

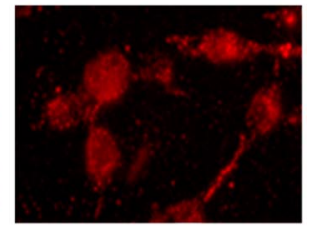

$3 \mathrm{hr}$ washout

Figure 10. Microglial cells proteolytically degrade fluorescently labeled $s A \beta$ upon internalization leaving behind the fluorescent chromophore. BV-2 microglial cells were incubated with $2 \mu \mathrm{g} / \mathrm{ml}$ of soluble Alexa488-labeled or -unlabeled $A \beta$ peptide and took up equivalent levels of both peptides, as measured by ELISA (data not shown) $A, B$, The degradation of the labeled or unlabeled $A \beta$ peptides was monitored using ELISA in both BV-2 microglial cells $(\boldsymbol{A})$ and primary microglia $(\boldsymbol{B})$. The cells were allowed to internalize $\mathrm{SA} \beta$ (labeled or unlabeled peptides) for $3 \mathrm{~h}$ (black bars); parallel cultures were washed and incubated for an additional $3 \mathrm{~h}$ in medium lacking $\mathrm{SA} \beta$ (striped bars). Mean $\pm \mathrm{SEM},{ }^{* * *} p<0.001,{ }^{*} p<0.05 . A, B, D, E$, Intracellular $A \beta$ levels were evaluated using ELISA $(\boldsymbol{A}, \boldsymbol{B})$, flow cytometry on the EPICS-XLMCL $(\boldsymbol{D})$, and immunofluorescence of Cy 3 labeled $A \beta(\boldsymbol{E})$. The black traces in $\boldsymbol{D}$ represent control nontreated cells. $\boldsymbol{C}$, In addition, levels of $A \beta$ in the media were monitored to control for resecretion of the peptide.

Conner SD, Schmid SL (2003) Regulated portals of entry into the cell. Nature 422:37-44

Coraci IS, Husemann J, Berman JW, Hulette C, Dufour JH, Campanella GK, Luster AD, Silverstein SC, El-Khoury JB (2002) CD36, a class B scavenger receptor, is expressed on microglia in Alzheimer's disease brains and can mediate production of reactive oxygen species in response to betaamyloid fibrils. Am J Pathol 160:101-112.

D’Amore JD, Kajdasz ST, McLellan ME, Bacskai BJ, Stern EA, Hyman BT (2003) In vivo multiphoton imaging of a transgenic mouse model of Alzheimer disease reveals marked thioflavine-S-associated alterations in neurite trajectories. J Neuropathol Exp Neurol 62:137-145.

Davalos D, Grutzendler J, Yang G, Kim JV, Zuo Y, Jung S, Littman DR, Dustin ML, Gan WB (2005) ATP mediates rapid microglial response to local brain injury in vivo. Nat Neurosci 8:752-758.

Deane R, Wu Z, Sagare A, Davis J, Du Yan S, Hamm K, Xu F, Parisi M, LaRue B, Hu HW, Spijkers P, Guo H, Song X, Lenting PJ, Van Nostrand WE, Zlokovic BV (2004) LRP/amyloid beta-peptide interaction mediates differential brain efflux of Abeta isoforms. Neuron 43:333-344.

Falcone S, Cocucci E, Podini P, Kirchhausen T, Clementi E, Meldolesi J (2006) Macropinocytosis: regulated coordination of endocytic and exocytic membrane traffic events. J Cell Sci 119:4758-4769.

Frieda S, Pearce A, Wu J, Silverstein RL (1995) Recombinant GST/CD36 fusion proteins define a thrombospondin binding domain. Evidence for a single calcium-dependent binding site on CD36. J Biol Chem 270:2981-2986.

Fujita H, Ishimura K, Matsuda H (1981) Freeze-fracture images on filipinsterol complexes in the thyroid follicle epithelial cell of mice with special regard to absence of cholesterol at the site of micropinocytosis. Histochemistry 73:57-63.

Gao YS, Hubbert CC, Lu J, Lee YS, Lee JY, Yao TP (2007) Histone deacetylase 6 regulates growth factor-induced actin remodeling and endocytosis. Mol Cell Biol 27:8637-8647.

Harris-White ME, Balverde Z, Lim GP, Kim P, Miller SA, Hammer H, Galasko D, Frautschy SA (2004) Role of LRP in TGFbeta2-mediated neuronal uptake of Abeta and effects on memory. J Neurosci Res 77:217-228.

Harris-White ME, Frautschy SA (2005) Low density lipoprotein receptorrelated proteins (LRPs), Alzheimer's and cognition. Curr Drug Targets CNS Neurol Disord 4:469-480.

Husemann J, Loike JD, Anankov R, Febbraio M, Silverstein SC (2002) Scav- enger receptors in neurobiology and neuropathology: their role on microglia and other cells of the nervous system. Glia 40:195-205.

Iadonato SP, Bu G, Maksymovitch EA, Schwartz AL (1993) Interaction of a $39 \mathrm{kDa}$ protein with the low-density-lipoprotein-receptor-related protein (LRP) on rat hepatoma cells. Biochem J 296:867-875.

Isberg RR, Hamburger Z, Dersch P (2000) Signaling and invasin-promoted uptake via integrin receptors. Microbes Infect 2:793-801.

Kim HJ, Chae SC, Lee DK, Chromy B, Lee SC, Park YC, Klein WL, Krafft GA, Hong ST (2003) Selective neuronal degeneration induced by soluble oligomeric amyloid beta protein. FASEB J 17:118-120.

Kirkham M, Parton RG (2005) Clathrin-independent endocytosis: new insights into caveolae and non-caveolar lipid raft carriers. Biochim Biophys Acta 1745:273-286.

Knauer MF, Soreghan B, Burdick D, Kosmoski J, Glabe CG (1992) Intracellular accumulation and resistance to degradation of the Alzheimer amyloid A4/beta protein. Proc Natl Acad Sci U S A 89:7437-7441.

Koenigsknecht J, Landreth G (2004) Microglial phagocytosis of fibrillar beta-amyloid through a betal integrin-dependent mechanism. J Neurosci 24:9838-9846.

Koistinaho M, Lin S, Wu X, Esterman M, Koger D, Hanson J, Higgs R, Liu F, Malkani S, Bales KR, Paul SM (2004) Apolipoprotein E promotes astrocyte colocalization and degradation of deposited amyloid-beta peptides. Nat Med 10:719-726.

Kreutzberg GW (1996) Microglia: a sensor for pathological events in the CNS. Trends Neurosci 19:312-318.

Kruth HS, Jones NL, Huang W, Zhao B, Ishii I, Chang J, Combs CA, Malide D, Zhang WY (2005) Macropinocytosis is the endocytic pathway that mediates macrophage foam cell formation with native low density lipoprotein. J Biol Chem 280:2352-2360.

Lacor PN, Buniel MC, Furlow PW, Clemente AS, Velasco PT, Wood M, Viola KL, Klein WL (2007) Abeta oligomer-induced aberrations in synapse composition, shape, and density provide a molecular basis for loss of connectivity in Alzheimer's disease. J Neurosci 27:796-807.

Lue LF, Kuo YM, Roher AE, Brachova L, Shen Y, Sue L, Beach T, Kurth JH, Rydel RE, Rogers J (1999) Soluble amyloid beta peptide concentration as a predictor of synaptic change in Alzheimer's disease. Am J Pathol 155:853-862.

Majumdar A, Cruz D, Asamoah N, Buxbaum A, Sohar I, Lobel P, Maxfield FR 
(2007) Activation of microglia acidifies lysosomes and leads to degradation of Alzheimer amyloid fibrils. Mol Biol Cell 18:1490-1496.

Maréchal V, Prevost MC, Petit C, Perret E, Heard JM, Schwartz O (2001) Human immunodeficiency virus type 1 entry into macrophages mediated by macropinocytosis. J Virol 75:11166-11177.

McDonald DR, Brunden KR, Landreth GE (1997) Amyloid fibrils activate tyrosine kinase-dependent signaling and superoxide production in microglia. J Neurosci 17:2284-2294.

McLean CA, Cherny RA, Fraser FW, Fuller SJ, Smith MJ, Beyreuther K, Bush AI, Masters CL (1999) Soluble pool of Abeta amyloid as a determinant of severity of neurodegeneration in Alzheimer's disease. Ann Neurol $46: 860-866$.

Mellman I (1996) Endocytosis and molecular sorting. Annu Rev Cell Dev Biol 12:575-625.

Mildner A, Schmidt H, Nitsche M, Merkler D, Hanisch UK, Mack M, Heikenwalder M, Brück W, Priller J, Prinz M (2007) Microglia in the adult brain arise from Ly-6C(hi)CCR2 $(+)$ monocytes only under defined host conditions. Nat Neurosci 10:1544-1553.

Mills IG (2007) The interplay between clathrin-coated vesicles and cell signalling. Semin Cell Dev Biol 18:459-470.

Nagele RG, D'Andrea MR, Anderson WJ, Wang HY (2002) Intracellular accumulation of beta-amyloid(1-42) in neurons is facilitated by the alpha 7 nicotinic acetylcholine receptor in Alzheimer's disease. Neuroscience 110:199-211.

Nichols B (2003) Caveosomes and endocytosis of lipid rafts. J Cell Sci 116:4707-4714

Nimmerjahn A, Kirchhoff F, Helmchen F (2005) Resting microglial cells are highly dynamic surveillants of brain parenchyma in vivo. Science 308:1314-1318.

Norbury CC (2006) Drinking a lot is good for dendritic cells. Immunology 117:443-451.

Paresce DM, Chung H, Maxfield FR (1997) Slow degradation of aggregates of the Alzheimer's disease amyloid beta-protein by microglial cells. J Biol Chem 272:29390-29397.

Parton RG, Richards AA (2003) Lipid rafts and caveolae as portals for endocytosis: new insights and common mechanisms. Traffic 4:724-738.

Ranson PA, Thomas WE (1991) Pinocytosis as a select marker of ramified microglia in vivo and in vitro. J Histochem Cytochem 39:853-858.

Rogers J, Lue LF (2001) Microglial chemotaxis, activation, and phagocytosis of amyloid beta-peptide as linked phenomena in Alzheimer's disease. Neurochem Int 39:333-340.

Saavedra L, Mohamed A, Ma V, Kar S, de Chaves EP (2007) Internalization of -amyloid Peptide by primary neurons in the absence of apolipoprotein e. J Biol Chem 282:35722-35732.

Sagare A, Deane R, Bell RD, Johnson B, Hamm K, Pendu R, Marky A, Lenting
PJ, Wu Z, Zarcone T, Goate A, Mayo K, Perlmutter D, Coma M, Zhong Z, Zlokovic BV (2007) Clearance of amyloid-beta by circulating lipoprotein receptors. Nat Med 13:1029-1031.

Sallusto F, Cella M, Danieli C, Lanzavecchia A (1995) Dendritic cells use macropinocytosis and the mannose receptor to concentrate macromolecules in the major histocompatibility complex class II compartment: downregulation by cytokines and bacterial products. J Exp Med 182:389-400

Saura J, Tusell JM, Serratosa J (2003) High-yield isolation of murine microglia by mild trypsinization. Glia 44:183-189.

Simakova O, Arispe NJ (2007) The cell-selective neurotoxicity of the Alzheimer's Abeta peptide is determined by surface phosphatidylserine and cytosolic ATP levels. Membrane binding is required for Abeta toxicity. J Neurosci 27:13719-13729.

Simard AR, Soulet D, Gowing G, Julien JP, Rivest S (2006) Bone marrowderived microglia play a critical role in restricting senile plaque formation in Alzheimer's disease. Neuron 49:489-502.

Stein MP, Dong J, Wandinger-Ness A (2003) Rab proteins and endocytic trafficking: potential targets for therapeutic intervention. Adv Drug Deliv Rev 55:1421-1437.

Stuart LM, Ezekowitz RA (2005) Phagocytosis: elegant complexity. Immunity 22:539-550.

Swanson JA, Watts C (1995) Macropinocytosis. Trends Cell Biol 5:424-428.

Tanzi RE, Bertram L (2005) Twenty years of the Alzheimer's disease amyloid hypothesis: a genetic perspective. Cell 120:545-555.

Vidricaire G, Tremblay MJ (2007) A clathrin, caveolae, and dynaminindependent endocytic pathway requiring free membrane cholesterol drives HIV-1 internalization and infection in polarized trophoblastic cells. J Mol Biol 368:1267-1283.

Wang J, Dickson DW, Trojanowski JQ, Lee VM (1999) The levels of soluble versus insoluble brain Abeta distinguish Alzheimer's disease from normal and pathologic aging. Exp Neurol 158:328-337.

Wang YJ, Zhou HD, Zhou XF (2006) Clearance of amyloid-beta in Alzheimer's disease: progress, problems and perspectives. Drug Discov Today 11:931-938.

Wehrle-Haller B, Imhof BA (2003) Actin, microtubules and focal adhesion dynamics during cell migration. Int J Biochem Cell Biol 35:39-50.

Wiedemann A, Linder S, Grassl G, Albert M, Autenrieth I, Aepfelbacher M (2001) Yersinia enterocolitica invasin triggers phagocytosis via betal integrins, CDC42Hs and WASp in macrophages. Cell Microbiol 3:693-702.

Wyss-Coray T, Loike JD, Brionne TC, Lu E, Anankov R, Yan F, Silverstein SC, Husemann J (2003) Adult mouse astrocytes degrade amyloid-beta in vitro and in situ. Nat Med 9:453-457. 